\title{
Analysis of freeze protection methods for recuperators used in energy recovery from exhaust air
}

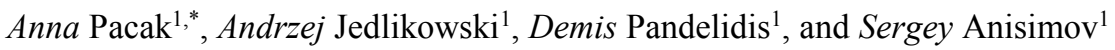 \\ ${ }^{1}$ Wrocław University of Science and Technology, Faculty of Environmental Engineering, Department \\ of Air Conditioning, Heating, Gas Engineering and Air Protection, ul. Norwida 4/6, \\ 50-373 Wrocław, Poland
}

\begin{abstract}
In this study theoretical analysis of the heat and mass transfer in counter-flow recuperators used for energy recovery in air handling units (AHU) under sub-zero outdoor air temperature operating conditions is presented. The most probable variants of year-round heat exchanger operation performance, which characterized by existence of three active heat and mass transfer zones ("dry", "wet", "frost"), and effect of the latent heat of water vapour condensation on the realization of these variants was determined. It was established, that the frost tends to take place with increasing temperature effectiveness of the heat exchanger. Two main techniques of the frost prevention (preheating and bypassing the outdoor airflow) were described and analysed. The values of critical outdoor temperatures and outdoor-to-return airflow rate ratio were determined on the base of parametric frosting limits analysis conducted under different inlet return airflow conditions. The comparison of the heat recovery efficiency and additional energy consumption for the air treatment in the AHU is presented.
\end{abstract}

\section{Introduction}

Nowadays the increased global energy consumption, many legal requirements and environmental protection, resulted in the rational management of energy resources. For this reasons, some actions are used to improve the effectiveness of existing and designed air conditioning and ventilation systems, well-known as the major consumers of electricity and heat [1]. For this reason, running costs of air conditioning system can be significantly reduced by implementing heat recovery. Heat recovery can be simply defined as the collection and re-use of waste heat arising from any technical or physical process that would otherwise be lost. This process can contribute to reduce the overall energy consumption and provide energy for other purposes [2]. The counter-flow heat exchanger can be used to perform this function in heat recovery technology.

Unfortunately, counter-flow heat exchangers are very often exposed to freezing when a heat recovery system is used in cold climates. Additionally, the presence of a frost layer in the heat exchanger core decreases significantly the heat recovery system performance. For this reason, frosting limits, freezing processes and different frost-preventing techniques

\footnotetext{
*Corresponding author: anna.pacak07@gmail.com
} 
have been extensively studied in recent years. Nasr et al. [3] analysed two heat exchangers: with a permeable membrane and impermeable membrane under frosting conditions. Wang et al. [4] described a "partial bypass" technique. The authors concluded that this action facilitates the heat transfer augmentation. Freund et al. [5] considered a preheated air strategy to change the air temperature and prevent frost formation on the coil. Besides, the authors compared the performance of five frost control strategies used for improve energy recovery in ventilation systems. Nasr et al. [6] studied the performance of two cross-flow heat exchangers under different operating conditions. They presented the values of frosting limit and defrosting time ratio. Moreover the authors evaluated the effects of two defrosting methods on energy consumption of ventilation in three cold cities. They concluded, that the air preheating method performs better than the outdoor air bypassing method for frost prevention.

Nevertheless, the problem of frost formation occurrence inside the counter-flow heat exchangers is still not solved and the most popular frost control techniques based on the outdoor air preheating or adjusting the outdoor-to-return airflow rate ratio are still facing challenges under extreme outdoor air temperature conditions.

\section{Theoretical analysis}

In order to analyse the counter-flow heat exchanger performance it is necessary to establish the most probable variants of its year-round operating conditions. The most often analysed variant is the " $d r y$ " variant of heat exchange performance. In this case, the surfaces of both heat exchanger channels are dry. Such conditions occur usually in the summer. Although the " $d r y$ " heat transfer conditions always occur in the outdoor air channel, the processes in the exhaust air channel may run differently [1]. For instance, there is a possibility of combined sensible and latent heat transfer on the surface of the return air channel, especially under the cold climate conditions. It means that a part of the plate surface is "wet" due to water vapour condensation in the form of water film. In this case the latent heat of the water vapour condensation can be additionally recovered. That is why heat recovery effectiveness is higher comparing to the "dry" mode. On the other hand, water vapour condensation in the form of the frost layer, which can be observed under sub-zero ambient air temperature conditions, reduces the heat exchanger efficiency and increases the pressure drop on the return airflow side, because the passage may be blocked by frost.

In this regard, a detailed analysis of coupled heat and mass transfer inside the counter-flow plate heat exchanger under frosting operating conditions was performed on the base of the original $\varepsilon$-NTU model [7]. Parametric numerical analyses were conducted to investigate heat and mass transfer in the counter-flow plate heat exchanger under sub-zero outdoor air temperature operating conditions. Three active heat and mass transfer areas were established in a counter-flow plate heat exchanger (see Fig. 1).

The detail analysis of these particular heat and mass transfer zones creation revealed the most probable variants of year-round operating conditions of the counter-flow heat exchanger. The implementation of the particular variant of heat and mass transfer inside the return airflow channel of the counter-flow plate heat exchanger depends upon the relations of the temperatures in two decisive zones on the return airflow channel surface (in the "cold zone" and in the "hot zone") and the value of the inlet return airflow dew point temperature (see Fig. 1). In order to illustrate and explain clearly the processes occurring inside the heat exchanger channels, the numerical simulations were carried out under conditions with constant inlet outdoor and return airflows temperatures $\left(t_{1 i}=-20^{\circ} \mathrm{C}, t_{2 i}=20^{\circ} \mathrm{C}\right)$ and variable inlet return airflow relative humidity $\left(\mathrm{RH}_{2 i}=(10-90) \%\right)$. The results of these numerical investigations are presented in Figs. 2(a) and (b). 


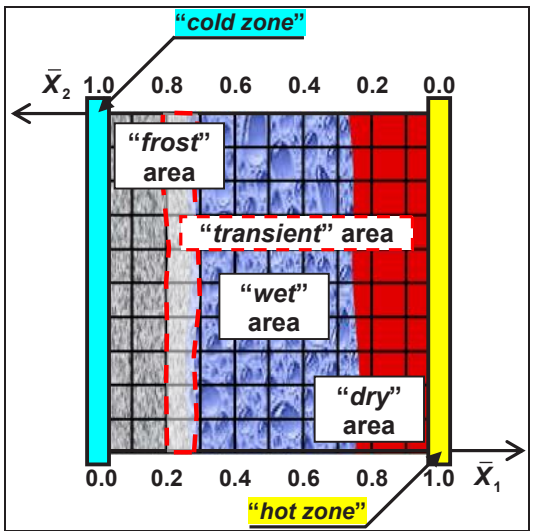

Fig. 1. Variants of heat and mass transfer zones.

a)

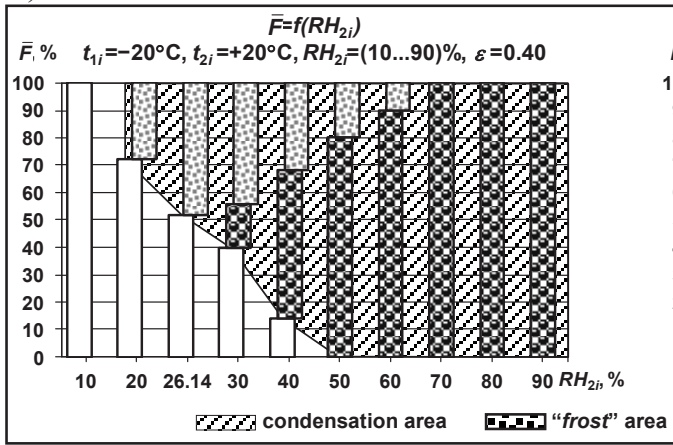

b)

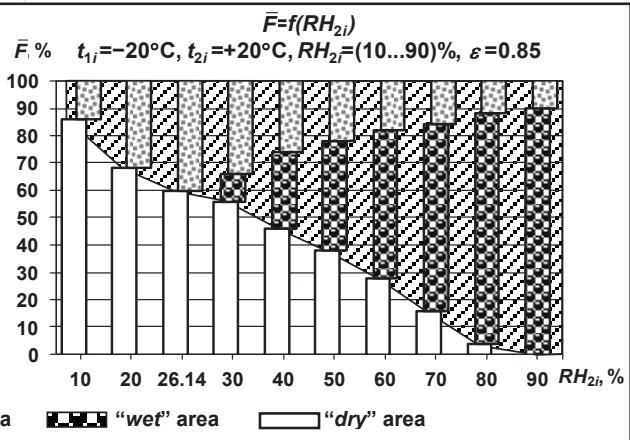

Fig. 2. The percentage distribution of the heat and mass transfer areas inside the counter-flow plate heat exchanger channels determined for the inlet outdoor airflow temperature $t_{1 i}=-20^{\circ} \mathrm{C}$ expressed as a function of the return air relative humidity (at the temperature effectiveness: a) $\eta=0.40$, b) $\eta=0.85$ ).

The data presented in Figs. 2(a) and (b) confirm clearly the obvious fact, that a higher value of the inlet return airflow relative humidity results in a larger area of the plate surface on which water vapour condensation takes place.

A "dry" zone at the entrance region dominates at low values of the return airflow relative humidity, but increasing the relative humidity $\mathrm{RH}_{2 i}$ reduces the dimension of this " $d r y$ " zone and at the values of $R H_{2 i}>(53-90) \%$ this zone disappears.

It can be also seen, that in the case of the sub-zero inlet return airflow dew point temperature $t_{2 i}^{D P}<0^{\circ} \mathrm{C}$, which corresponds to the relative humidity $R H_{2 i} \leq 26.15 \%$, the water vapour condensation may occur only in the form of the frost layer and increasing the inlet relative humidity $R H_{2 i}$ under such conditions reduces " $d r y$ " zone at the expense of increasing the "frost" zone. In the case of the above-zero dew point temperature of the return air $\left(t_{2 i}^{D P}>0^{\circ} \mathrm{C}\right)$ the water vapour condensation may be observed both in the form of the water film and in the form of the frost layer. It should be noted, that the "frost" zone reaches maximum at the value of inlet return airflow dew point temperature equalled to $t_{2 i}^{D P}=0^{\circ} \mathrm{C}\left(R H_{2 i}=26.14 \%\right)$. At first sight, it could be surprising, that the dimension of the "frost" zone decreases with the increasing the inlet relative humidity of the return air higher 
than $26.14 \%$. The reason for this phenomenon can be explained by the analysis of the interfacial heat and mass transfer in the return airflow channel. The latent heat of water vapour condensation in the form of liquid film increases the local plate temperature in the return air channel. In turn, a higher value of the local plate temperature leads to a smaller air side temperature gradient at the gas-liquid interface and thus a lower value of the local sensible heat flux and, as a consequence, a smaller temperature drop of the return air in its flow direction. That is why the local plate temperature at the exit region of return airflow channel increases with increasing $\mathrm{RH}_{2 i}$ and thus a frost formation occurs on the more remote exit region of the plate surface in the return air channel [7].

So, an increase of inlet relative humidity of the return air in the range of value from $10 \%$ to $90 \%$ leads to an increase of the total water vapour condensation zone due to natural reduction of the "dry" zone. Increasing the inlet relative humidity of the return air under such conditions causes a decrease of the "frost" zone at the exit region due to preliminary expansion of the "wet" zone, although the total area of condensation is increasing. Moreover, it should be noted, that increasing the inlet relative humidity of the return in the range of $\mathrm{RH}_{2 i}=10-90 \%$ causes an increase of the temperature effectiveness $\varepsilon$ due to additional latent heat recovery at the expanse of the condensation zone expansion [7].

It can be seen in Fig. 2(a), that in the case of the minimum temperature effectiveness $(\varepsilon=0.40)$ frost-free operation is observed only at the values of the return air relative humidity in the following ranges $R H_{2 i} \leq 10 \%$ and $R H_{2 i} \geq 70 \%$ but at maximum temperature effectiveness ( $\varepsilon=0.85$, see Fig. 2(b)) frost-free operation is completely impossible under analysed range of the return air relative humidity variations.

The reason of such heat exchanger performance behaviour is that a higher temperature effectiveness results in a higher risk of frost formation at the expense of the temperature decrease of the outlet return airflow and plate surface in the "cold zone" (below water freezing point temperature). It should be noted, that the largest "frost" area occurs under conditions corresponding to the range of the return air relative humidity $\mathrm{RH}_{2 i}=20-50 \%$. Unfortunately, this range corresponds to the normal (recommended) indoor air conditions in winter season.

\section{Frost prevention methods}

There are two typical methods of frosting protection for counter-flow plate heat exchangers: preheating of intake (outdoor) air and bypassing the outdoor airflow.

Preheating of ambient air is usually realized in electrical air heater to the safe values of the inlet outdoor air temperature (called as threshold temperature) defined as minimum intake air temperature at which the local temperature of the plate in the "cold zone" is above $0^{\circ} \mathrm{C}$. In this case there is no any frost area on the heat exchanger's surface. The values of these temperatures are presented in Table 1.

In the case of bypassing, the ratio of the outdoor airflow to exhausted airflow is reduced to the level at which frost layer is not observed on the plate surface of the return airflow channel. Threshold values of the outdoor airflow to returned ratio are presented in the Tab. 2 for different values of outdoor air temperature. 
Table 1. The threshold values of the outdoor air temperature for return air temperature equal to $t_{2 i}=20^{\circ} \mathrm{C}$ and different temperature effectiveness of the counter-flow plate heat exchanger used for energy recovery from exhaust air (without bypassing $G_{1} / G_{2}=1.0$ ) [7].

\begin{tabular}{|c|c|c|c|c|c|}
\hline \multicolumn{2}{|c|}{ Return air parameters } & \multicolumn{4}{|c|}{ Outdoor air parameters } \\
\hline $\begin{array}{c}\text { relative } \\
\text { humidity, } \\
R H_{2 i}, \%\end{array}$ & $\begin{array}{c}\text { dew point } \\
\text { temperature, } \\
t_{2 i}^{D P},{ }^{\circ} \mathrm{C}\end{array}$ & \multicolumn{2}{|c|}{$\begin{array}{c}\text { the threshold values of outdoor air temperature } \\
t \text { trshld },{ }^{\circ} \mathrm{C} \text {, for different temperature } \\
\text { effectiveness of counter-flow plate heat } \\
\text { exchanger }\end{array}$} \\
\hline & & $\varepsilon=0.50$ & $\varepsilon=0.60$ & $\varepsilon=0.70$ & $\varepsilon=0.80$ \\
\hline 10 & -12.5 & -23.3 & -20.6 & -18.2 & -16.1 \\
\hline 20 & -3.6 & -11.5 & -9.5 & -7.7 & -6.2 \\
\hline 26.14 & 0.0 & -6.6 & -4.9 & -3.5 & -2.2 \\
\hline 30 & +1.9 & -7.6 & -5.8 & -4.3 & -3.0 \\
\hline 40 & +6.0 & -10.0 & -8.1 & -6.5 & -5.0 \\
\hline 50 & +9.3 & -12.5 & -10.5 & -8.7 & -7.1 \\
\hline 60 & +12.0 & -15.0 & -12.8 & -10.9 & -9.2 \\
\hline 70 & +14.4 & -17.5 & -15.1 & -13.1 & -11.2 \\
\hline 80 & +16.4 & -20.0 & -17.5 & -15.3 & -13.3 \\
\hline 90 & +18.3 & -22.5 & -19.9 & -17.5 & -15.4 \\
\hline
\end{tabular}

Table 2. The threshold values of the outdoor airflow to returned ratio $\left(G_{1} / G_{2}\right)$ at different values of outdoor air temperature for return air temperature equal to $t_{2 i}=20^{\circ} \mathrm{C}$ and different heat recovery efficiency $\eta$ of the counter-flow plate heat exchanger [7].

\begin{tabular}{|c|c|c|c|c|c|c|c|c|c|}
\hline \multirow{2}{*}{$\begin{array}{c}\text { Return air } \\
\text { parameters } \\
\\
\text { relative } \\
\text { humidity, } \\
\mathrm{RH}_{2 i}, \%\end{array}$} & \multirow{2}{*}{$\begin{array}{l}\text { Threshold } \\
\text { values of } \\
\text { the } \\
\text { outdoor } \\
\text { airflow to } \\
\text { returned } \\
\text { ratio } \\
\left(G_{1} / G_{2}\right)\end{array}$} & \multicolumn{8}{|c|}{ Outdoor air temperature, ${ }^{\circ} \mathrm{C}$} \\
\hline & & $t_{1 i}$ & $\eta$ & $t_{1 i}$ & $\eta$ & $t_{1 i}$ & $\eta$ & $t_{1 i}$ & $\eta$ \\
\hline \multirow{6}{*}{40} & 1.00 & -10.0 & 0.50 & -8.1 & 0.60 & -6.5 & 0.70 & -5.0 & 0.80 \\
\hline & 0.80 & -11.2 & 0.47 & -9.3 & 0.55 & -7.7 & 0.63 & -6.4 & 0.71 \\
\hline & 0.60 & -12.8 & 0.42 & -11.0 & 0.48 & -9.4 & 0.53 & -8.1 & 0.58 \\
\hline & 0.40 & -16.6 & 0.34 & -13.9 & 0.37 & -11.6 & 0.40 & -9.6 & 0.43 \\
\hline & 0.20 & -22.2 & 0.20 & -18.0 & 0.21 & -14.3 & 0.22 & -10.7 & 0.23 \\
\hline & 0.05 & -28.5 & 0.06 & -23.1 & 0.06 & -18.2 & 0.06 & -13.3 & 0.06 \\
\hline \multirow{6}{*}{50} & 1.00 & -12.5 & 0.50 & -10.5 & 0.60 & -8.7 & 0.70 & -7.1 & 0.80 \\
\hline & 0.80 & -13.8 & 0.46 & -11.8 & 0.55 & -10.1 & 0.63 & -8.7 & 0.70 \\
\hline & 0.60 & -15.7 & 0.41 & -13.8 & 0.47 & -12.0 & 0.53 & -10.7 & 0.57 \\
\hline & 0.40 & -19.8 & 0.33 & -17.0 & 0.36 & -14.5 & 0.39 & -12.3 & 0.42 \\
\hline & 0.20 & -26.5 & 0.19 & -21.9 & 0.20 & -17.7 & 0.21 & -13.7 & 0.22 \\
\hline & 0.05 & -36.9 & 0.05 & -29.7 & 0.06 & -23.2 & 0.06 & -16.6 & 0.06 \\
\hline \multirow{6}{*}{60} & 1.00 & -15.0 & 0.50 & -12.8 & 0.60 & -10.9 & 0.70 & -9.2 & 0.80 \\
\hline & 0.80 & -16.4 & 0.46 & -14.3 & 0.54 & -12.4 & 0.62 & -10.9 & 0.70 \\
\hline & 0.60 & -18.5 & 0.41 & -16.4 & 0.47 & -14.6 & 0.52 & -13.1 & 0.56 \\
\hline & 0.40 & -23.0 & 0.33 & -20.0 & 0.36 & -17.4 & 0.39 & -15.1 & 0.42 \\
\hline & 0.20 & -32.2 & 0.19 & -26.7 & 0.20 & -21.6 & 0.21 & -16.7 & 0.22 \\
\hline & 0.05 & -45.2 & 0.05 & -36.3 & 0.05 & -28.2 & 0.06 & $\begin{array}{l}-19.8 \\
\end{array}$ & 0.06 \\
\hline
\end{tabular}

Temperature effectiveness and heat recovery efficiency for the purpose of frost protection analysis were defined as follows: 
Temperature effectiveness of heat exchanger:

$$
\varepsilon=\frac{t_{1 o}-t_{1 i}}{t_{2 i}-t_{1 i}}
$$

Heat recovery efficiency:

$$
\eta=\frac{t_{1 o}-t_{1 i}}{t_{2 i}-t_{1 i}}\left(\frac{G_{1} \cdot c_{p 1}}{G_{2} \cdot c_{p 2}}\right)
$$

From the above results, one can see that the values of heat recovery efficiency $\eta$ and threshold ratio of the outdoor airflow to exhausted drop with decreasing of the ambient air temperature.

\section{Heat recovery efficiency analysis}

The comparison of the heat recovery efficiency and energy demand for the air treatment in the AHU with counter-flow plate heat exchanger under two examined frosting control strategies is presented in Fig. 3.

a)

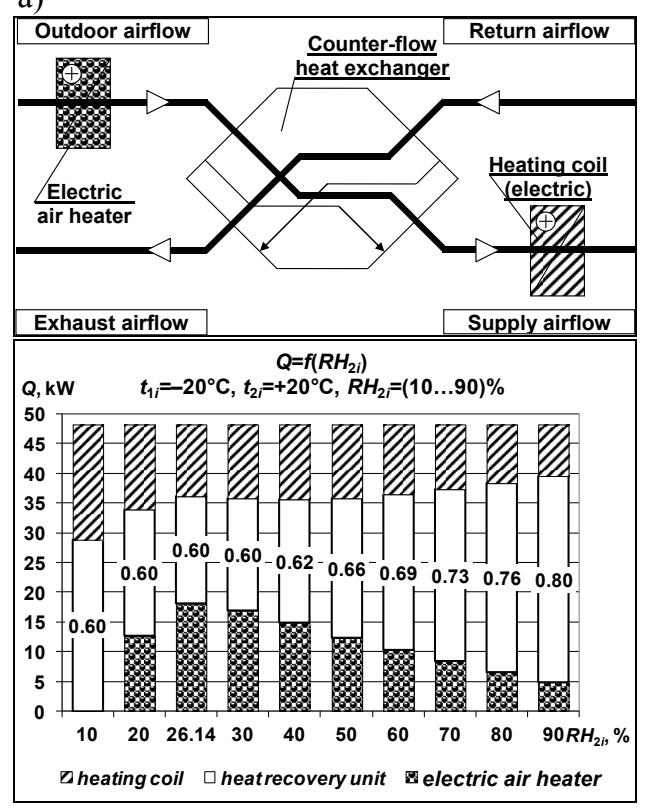

b)
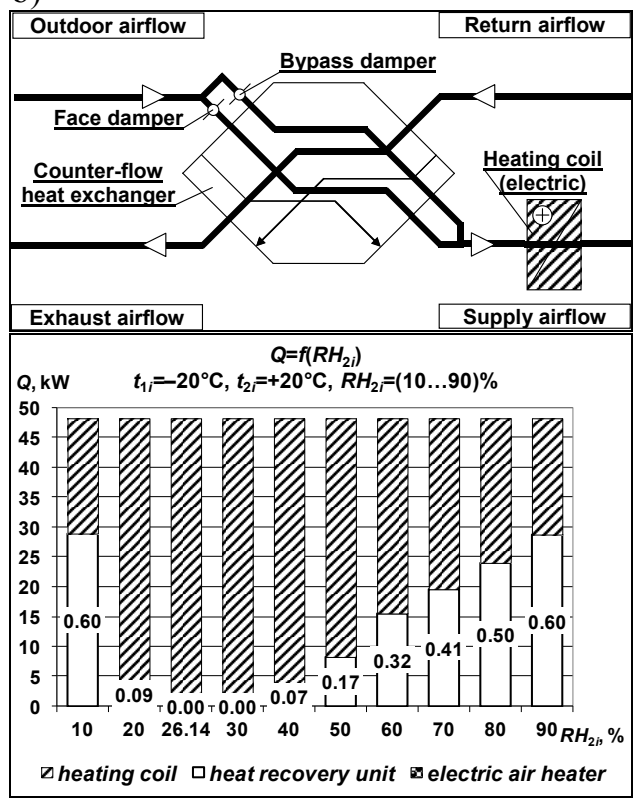

Fig. 3. The comparison of the heat recovery and additional energy consumption for the air treatment in AHU with counter-flow plate heat exchanger expressed as a function of the return air relative humidity under different frosting control methods: (a) preheating (b) bypass damper system.

The energy demand for the air treatment in the AHU was calculated for the value of the volumetric airflow rate equalled to $1 \mathrm{~m} / \mathrm{s}$. As one can see in Fig. 3, the performance of the heat exchanger equipped with the bypass dampers is characterized by very low heat recovery efficiency. In this regard, the AHU with the heat exchanger equipped with the bypass dampers needs to provide significantly more total power for the air treatment than in the case of the preheating. 
To sum it up, it can be said that the performance of preheating technique is more efficient than and bypass dampers method of frosting protection.

\section{Conclusions}

In this study a theoretical analysis of the heat and mass transfer in the counter-flow plate heat exchanger used for energy recovery in AHU under sub-zero outdoor air temperature operating conditions was presented. Two main techniques of the frost prevention (preheating and bypassing the outdoor airflow) were described and analysed on the base of the modified $\varepsilon$-NTU model. Unique aspects of the most probable variants of year-round heat exchanger operation performance, characterized by existence of three active heat and mass transfer areas ("dry", "wet", "frost"), were revealed. The results of the conducted investigations are summarized as follows:

- The formation and variability of different active heat and mass transfer zones strongly depends on the inlet return air relative humidity and inlet outdoor airflow temperature.

- The values of critical outdoor air temperatures and outdoor-to-return airflow rate ratio for frost-free operating conditions were determined at different inlet return airflow parameters (see Tab. 1 and 2).

- Inlet return airflow dew point temperature plays crucial role in the frosting limit. The most unfavourable operating conditions at sub-zero outdoor air temperature occur at the value of inlet return air dew point temperature $t_{2 i}^{D P}=0^{\circ} \mathrm{C}$. In the case of inlet return air temperature $t_{2 i}=+20^{\circ} \mathrm{C}$ such conditions correspond to the relative humidity $\mathrm{RH}_{2 i}=26.14 \%$. Unfortunately, this air relative humidity corresponds to recommended indoor air conditions in winter season.

- The frost tends to take place with increasing temperature effectiveness $\varepsilon$ (heat recovery efficiency $\eta$ ) of the heat exchanger.

The obtained results may help to reduce the costs of the supply air treatment in AHU and increase the period of time when heat recovery units are effectively operated. However, more research is needed to find the best frost protection method, which allows for maximum heat recovery from return air.

The conference participation was financed from the statutory funds of Faculty of Environmental Engineering, Wroctaw University of Science and Technology from the project 0401/0066/16.

\section{Nomenclature}

$c_{p}$ - specific heat capacity, $\mathrm{J} /(\mathrm{kg} \cdot \mathrm{K}) ; F$ - heat or heat and mass transfer surface area, $\mathrm{m}^{2} ; F_{o}$ - total surface area, $\mathrm{m}^{2} ; \bar{F}=\left(F / F_{o}\right) \cdot 100 \%$ - heat or heat and mass transfer surface area relates to total surface area, $\% ; G$-moist air mass flow rate, $\mathrm{kg} / \mathrm{s} ; t$ - temperature, ${ }^{\circ} \mathrm{C} ; L_{X_{1}}$-channel of heat exchanger in $X_{1}$ direction, $\mathrm{m} ; L_{X_{2}}$ - channel length of heat exchanger in $X_{2}$ direction, $\mathrm{m} ; Q$ - heating capacity, $\mathrm{kW} ; X_{1}$ - Cartesian coordinate in $X_{1}$ direction (along outdoor airflow direction), $\mathrm{m}$; $\bar{X}_{1}=X_{1} / L_{X_{1}}$ - relative $X_{1}$ coordinate, dimensionless; $X_{2}$ - Cartesian coordinate in opposite to $X_{1}$ direction, $\mathrm{m}$ (along return airflow direction); $\bar{X}_{2}=X_{2} / L_{X_{2}}$ - relative $X_{2}$ coordinate, dimensionless; $\alpha$ - convective heat transfer coefficient, $\mathrm{W} /\left(\mathrm{m}^{2} \mathrm{~K}\right) ; \varepsilon$-temperature effectiveness of heat exchanger, dimensionless; $\eta$ - heat recovery efficiency, dimensionless. 
Subscripts: 1 - outdoor airflow; 2 - return airflow; $D P$-referenced to dew point temperature; $i$ - inlet; $o$ - outlet; trshld - threshold value of outdoor air temperature.

Acronyms: AHU - Air Handling Unit; NTU $=\alpha F /\left(G c_{p}\right)$-Number of Transfer Units; $R H$ - Relative Humidity, \%.

\section{References}

1. S. Anisimov, A. Jedlikowski, M. Skrzycki, Proceedings of the Xth International Scientific Conference „Quality of Indoor Air and Environment”, 302-308, Volgograd-Budapest May 13-20.2012,

2. CARBON TRUST, Published in the United Kingdom, August 2011, accessed August 21, 2013: http://www.carbontrust.com/resources/guides/energy efficiency/heatrecovery, http://www.carbontrust.com/media/31715/ctg057_heat_recovery.pdf

3. M.R. Nasr, F. Fathieh, D. Kadylak, R. Huizing, R.W. Besant, C.J. Simonson, Exp. Thermal Fluid Sci. 77, 100-115 (2016)

4. C.-C. Wang, K.-Y. Chen, J.-S. Liaw, C.-Y. Tseng, Int. J. Heat Mass Transf. 55, 5367-5372 (2012)

5. S. Freund, S.A. Klein, D.T. Reindl, HVAC\&R Res. J. 9, 493-508 (2003)

6. M.R. Nasr, M. Kassai, G. Ge, C.J. Simonson, Appl. Energy 151, 32-40 (2015)

7. A. Jedlikowski, S. Anisimov, J. Danielewicz, M. Karpuk, D. Pandelidis, Int. J. Heat Mass Transf. 108, 585-613 (2017) 